\title{
A regional register for inherited cancers
}

\author{
Mary Littler, Peter S Harper
}

Registers for familial tumours have existed in various forms for several years. ${ }^{1}$ Some have been primarily epidemiological, with the aim of detecting underlying causative factors, and others have been restricted to individual rare tumours treated in specialist centres, existing primarily to help in the management of the disease. Various forms of genetic register have likewise been described: some general and some restricted to specific genetic disorders. ${ }^{23}$ None has so far attempted to ascertain and monitor in a defined region the important tumours that are determined by a single gene with the view of reducing the incidence of inherited cancers and their complications. We describe the setting up of such a register in Wales for five main forms of inherited cancer and the results during its first two years.

\section{Background and methods}

Until 1985 no specific or comprehensive system of recording or monitoring inherited tumours existed in Wales, though specific skills and interest existed, notably in the pathology and management of endocrine

Br.Med F 1989;298: 1689-91

TABLE I - Inherited tumour syndromes included on register

\begin{tabular}{|c|c|c|}
\hline & $\begin{array}{l}\text { Site of principal } \\
\text { malignant tumours }\end{array}$ & $\begin{array}{c}\text { Chromosomal } \\
\text { localisation }\end{array}$ \\
\hline $\begin{array}{l}\text { Retinoblastoma } \\
\text { von Hippel-Lindau disease } \\
\text { Multiple endocrine neoplasia type II } \\
\text { Familial adenomatous polyposis } \\
\text { Naevoid basal cell carcinoma syndrome }\end{array}$ & $\begin{array}{l}\text { Eye } \\
\text { Cerebellum, kidney, adrenal medulla } \\
\text { Thyroid, adrenal medulla } \\
\text { Colon } \\
\text { Skin, ovary, brain }\end{array}$ & $\begin{array}{c}13 q \\
3 q \\
10 \\
5 q \\
?\end{array}$ \\
\hline
\end{tabular}

TABLE II -Special approaches to ascertainment of tumours

\begin{tabular}{ll}
\hline Tumour & \multicolumn{1}{c}{ Approach } \\
\hline Retinoblastoma & $\begin{array}{l}\text { Ophthalmology records and referrals } \\
\text { Special school for visually handicapped } \\
\text { Moorfields Eye Hospital, London } \\
\text { Neuropathology records }\end{array}$ \\
von Hippel-Lindau disease & Neurology and ophthalmology departments \\
& Thyroid tumour register \\
Multiple endocrine neoplasia type II & Endocrinologists \\
& Consultant surgeons \\
Familial adenomatous polyposis & St Mark's Hospital polyposis register \\
& Dental hospital \\
Naevoid basal cell carcinoma syndrome & Dermatology department \\
&
\end{tabular}

TABLE III -Numbers of affected subjects and subjects at risk on register with numbers of families and numbers of subjects from whom DNA has been isolated

\begin{tabular}{|c|c|c|c|c|c|}
\hline & \multicolumn{2}{|c|}{ Affected } & \multirow{2}{*}{$\begin{array}{l}\text { Unaffected } \\
\text { but at risk }\end{array}$} & \multirow[b]{2}{*}{ Families } & \multirow{2}{*}{$\begin{array}{c}\text { DNA } \\
\text { isolated }\end{array}$} \\
\hline & Total & Living & & & \\
\hline Retinoblastoma & 50 & 48 & 16 & 43 & 66 \\
\hline von Hippel-Lindau disease & 18 & 11 & 46 & 10 & 14 \\
\hline Multiple endocrine neoplasia type II & 8 & 7 & 40 & 8 & 14 \\
\hline Familial adenomatous polyposis & 48 & 32 & 58 & 25 & 19 \\
\hline Naevoid basal cell carcinoma syndrome & 8 & 8 & 7 & 4 & 5 \\
\hline Total & 132 & 106 & 167 & 90 & 118 \\
\hline
\end{tabular}

tumours. Treatment of some forms-for example, retinoblastoma and familial adenomatous polyposiswas carried out partly in centres outside Wales, though there was no coordinated mechanism for ensuring genetic counselling of patients or relatives. A well developed regional medical genetics service existed, with registers established for Huntington's disease and several other genetic disorders, but inherited tumours were not included on any of these registers.

In late 1985 the funding of a post through the United Kingdom Cancer Families Study Group allowed a regional register for inherited cancers to be set up systematically in this institute. The disorders included initially all followed autosomal dominant inheritance and are listed in table I, their choice being based on criteria discussed later.

The tumours were ascertained from various sources and for the whole of Wales, though the information collected remains incomplete, especially for north Wales. The diagnostic Hospital Activities Analysis data for the whole of Wales and the records of the regional medical genetics service were used for all the disorders, and appropriate consultants were also contacted. The specific sources listed in table II were also used for the individual conditions, and all diagnoses were checked against hospital records. When subjects were being considered for inclusion on the register their family doctor and consultant concerned were contacted before they were approached.

At first patients were generally interviewed in their homes. As well as permission being sought to place them on the register, basic identification and diagnostic information were recorded in all cases, in addition to more selected information about the disorder.

All data were recorded on a dedicated microcomputer (IBM XT) using the system dbase III, which allowed the program to be altered easily and additional fields to be added if required. A main file was created for each affected patient, with a linked file for unaffected relatives at risk.

Recall of patients or relatives for examination or investigation was organised in cooperation with the doctor concerned. The register allowed automatic prompting when recall was due, subjects being selected according to their name, identifying number, or family number.

\section{Results}

Two years after the register was started (late 1988) it contained data on 132 affected patients from 90 different families, as well as information on a further 167 family members. Table III summarises the data on the five disorders. In addition, DNA was isolated from 118 subjects (41 patients and 77 relatives). Of the affected patients on the register, 57 were under regular surveillance.

\section{RETINOBLASTOMA}

Fifty patients with retinoblastoma from 43 families 
were entered on the register; 48 were alive and 20 were traced through the records of Moorfields Eye Hospital, where specialist treatment had been undertaken. The disease was bilateral in 31 patients and disease had occurred in more than one family member of four of the 19 patients with unilateral disease. In three cases (two of unilateral disease) a visible deletion of chromosome 13 was detected on chromosome analysis, so that a minimum of 37 cases were potentially familial rather than the result of somatic mutation alone. No instance of tumour elsewhere has been detected to date in these patients.

The follow up protocol for patients and infants at high risk of retinoblastoma includes indirect ophthalmology every three months until 2 years of age, and this is reduced to every four until the age of 4 years and to every six months until the age of 10 years. Blood is taken for chromosome analysis, estimation of esterase $\mathrm{D}$ activity, and isolation of DNA in all cases.

Case I-A 16 month old boy was seen initially because of developmental delay associated with hypotonia. The diagnosis was not specific, but a neurodegenerative disorder was suspected. A lesion noted in the right fundus was thought at this stage to be due to infection with toxocara. A chromosomal study showed a deletion in chromosome 13 that extended from band q13.2 to $22 \cdot 1$ and included the site of the retinoblastoma locus. Further ophthalmological investigation confirmed a retinoblastoma in the right eye, which was enucleated. The left eye was regularly reviewed. General progress of motor and social development has remained considerably delayed.

In this case recognition of the chromosome deletion allowed diagnosis of the retinoblastoma and appreciation of the risk to the other eye with no family history of the disorder. The fact that chromosomes were normal in his parents and healthy sibling excluded a significant risk to future children. The deletion also explained the generally delayed development and suggested a poor prognosis.

\section{VON HIPPEL-LINDAU DISEASE}

A previous study of von Hippel-Lindau disease in south Wales, which was based principally on neurological and neuropathology records,${ }^{4}$ was the principal source for ascertaining this disorder and thus has probably biased the types of tumour seen in our patients. Of the 18 patients on the register, 16 had cerebellar tumours, 11 retinal lesions, seven renal carcinoma, and two adrenal phaeochromocytoma.

Follow up for affected patients is life long and entails an annual clinical assessment, indirect ophthalmology, and estimation of urinary vanillylmandelic acid and metadrenaline excretion with cranial and abdominal computed tomography every alternate year as recommended by Huson et al.$^{4}$ In unaffected relatives at risk clinical and ophthalmological assessment is performed annually from the age of 5 years, urine studies from the age of 10 years, and radiology from the age of 15 years, studies being discontinued after the age of 50 .

Case 2-A 17 year old girl who presented to the neurology department with headache was found to have a cerebellar haemangioblastoma, which was successfully removed. von Hippel-Lindau disease was not dignosed until she developed a retinal haemangioblastoma aged 21 . Screening of first degree relatives showed her brother to have an asymptomatic renal carcinoma, which was removed. Both siblings remained well and are monitored annually. During the family investigation it transpired that the mother had been diagnosed as having von Hippel-Lindau disease after developing a cerebellar tumour 20 years previously. The lack of a register meant that this information was not known and the younger generation had received no information on their risk.
MULTIPLE ENDOCRINE NEOPLASIA TYPE II

Multiple endocrine neoplasia type II is characterised by a high frequency of medullary thyroid cancer and adrenal phaeochromocytoma and is a longstanding research interest of the departments of pathology, medicine, and endocrine surgery in Cardiff. Eight patients were entered. on to the register with this disorder. This small number reflects the fact that only patients with multiple tumours or more than one affected family member were accepted on to the register because the proportion of cases of isolated medullary thyroid cancer that may be inherited is uncertain. The surveillance protocol includes annual provocation tests with pentagastrin and estimations of urinary vanillylmandelic acid and metadrenaline excretion from the ages of 9 to 35 in relatives at risk and indefinitely in affected patients.

\section{FAMILIAL ADENOMATOUS POLYPOSIS}

Forty eight patients with familial adenomatous polyposis from 25 families were entered on to the register; only 32 were alive. Twenty four patients were traced through the register for this disorder maintained at St Mark's Hospital, London. Fourteen affected patients showed desmoid or other tumours suggestive of the more generalised Gardner's syndrome, though this is not now considered to be a distinct disorder. The current protocol for relatives at risk includes annual colonoscopy from the age of 13 years and colonoscopy every six months for patients with ileorectal anastomosis or restorative proctocolectomy. Ophthalmic assessment is now being introduced in view of the recent recognition of congenital hypertrophy of the retinal pigment epithelium as an early sign in affected people. $^{5}$

Case 3-The proband was placed on the register after undergoing ileorectal anastomosis for polyposis coli, after which his two siblings were both found also to be affected. Although their mother had been recognised as having polyposis before she died of bowel cancer, they had not realised that they were themselves at risk. The proband's son had died of hepatoblastoma aged 7 years; it had not been appreciated that this might have been related to the polyposis in the family or that the remaining child was at risk of polyposis. Six living children of the three affected siblings are currently under regular surveillance. DNA has been isolated from all family members and may help to determine which subjects in the youngest generation have inherited the gene.

NAEVOID BASAL CELL CARCINOMA SYNDROME (GORLIN'S SYNDROME)

The naevoid basal cell carcinoma syndrome is comparatively rare and characterised by multiple basal cell tumours, jaw cysts, and less frequent ocular defects and ovarian tumours. It was ascertained principally through the dental hospital. The protocol for review ing patients entails annual dermatological, dental, and ophthalmic assessments.

\section{Discussion}

The register has been in operation only for a short time and is still developing, but several points are already clear. Firstly, it is feasible for a single worker (in this instance a graduate scientist without medical training) based in the regional genetics centre and liaising closely with various clinicians to compile and maintain a register of this type without the need for extensive computer and clerical support. All the clinicians concerned, including ophthalmologists, neurologists, and general, endocrine, and dental surgeons, found the existence of the register and the service provided helpful and were happy for their patients to 
be included on it. The extended family tracing made possible by the register has already resulted in the detection and treatment of previously unrecognised tumours, as illustrated in the three cases described.

Secondly, the disorders included here, though not common, affect a considerable number of people who require follow up for appropriate management and include not only currently healthy subjects at risk of the disorder but also affected subjects at risk of developing further tumours. Almost all the tumour types produced by these disorders are potentially curable if detected early, and the screening investigations entailed are comparatively non-invasive in that they do not require the patient to be admitted to hospital. Before the register existed some clinicians were following individual patients regularly, but we consider that our unified register with its automatic prompting for recall provides an efficient and flexible system that still permits individiual clinicians to follow and manage patients in the way they consider best.

Thirdly, the register has allowed systematic genetic counselling to reach extended families for the first time. Few patients and even fewer relatives at risk had previously had adequate information on genetic risk; this applied particularly to the extended families of patients with retinoblastoma and polyposis who had been seen at specialist centres based in London; in such cases often only the patient and immediate family had been seen.

Isolation of DNA from a venous blood sample (or less commonly from the tumour) and its storage was built into our protocol from the start, even though at the beginning retinoblastoma was the only disorder for which there was any information on gene localisation. The rapidity of gene mapping and molecular genetic developments has seen the genes in all the disorders concerned (apart from the naevoid basal cell carcinoma syndrome) firmly localised during the past two years. ${ }^{6.9}$ In the case of retinoblastoma the gene has been cloned to allow specific presymptomatic (and, if requested, prenatal) diagnosis. ${ }^{10} 11$ These developments enhance the importance of the register and should in future modify its action by allowing many subjects to be identified early as being free of risk because of not having inherited the gene. Meanwhile, systematic banking of DNA ensures that this information is not lost should the patient die.

In choosing the initial disorders on which to base our register we have deliberately been restrictive in the criteria used. Tumour syndromes that were important, potentially life threatening, and treatable were chosen so that the register might have a clear benefit for the patients concerned. The conditions all showed an extremely high frequency of tumours (often multiple); other disorders with an appreciable but lower rate of malignancy such as neurofibromatosis and tuberous sclerosis were excluded, as were rare, recessively inherited disorders predisposing to malignancy such as ataxia telangiectasia. The prevalence of the disorder was also a consideration, though influenced in some cases by local considerations; the disorders included probably comprise over half the tumours determined by a single gene that are currently recognised. Until now we have not tried to cover familial clusters in which there is no clear indication of specific mendelian inheritance, partly because it is difficult to distinguish such clusters from the many common tumours showing some familial tendency, partly because of the difficulty in accurately assessing genetic risks in such families. Specific genes will probably be identified for some of these conditions in the future, in which case they could be suitable for inclusion.

We regard our current register and its associated monitoring system as a pilot study which will undoubtedly change in response to new developments. Further disorders will probably be added, and those that have been currently ascertained are not yet complete. We consider the regional nature of the register to be important as it corresponds to the pattern of many other specialist services and affects sufficiently few clinicians to permit personal contact between them and those concerned with the register. Though for some rare tumours a national (United Kingdom) register may have an important role in providing skill for monitoring progress in the disorder, we are not convinced that such registers can satisfactorily deal with the tracing and investigation of the extended family and particularly genetic counselling. Wales, functioning as a single health region with a population of around three million and a single medical school, seems to be an appropriate population base for a register of this type.

It will be some years before our register can be accurately assessed in terms of its value in preventing cancer. Some of the preventive value is to be expected in terms of the numbers of second tumours detected and treated in patients already affected and some in the early detection of treatable tumours in those previously unaffected but at risk. Molecular probes will allow earlier presymptomatic detection (and exclusion) of gene carriers, and prenatal diagnosis may prove to have a role in reducing transmission of the genes concerned. All of these aspects should be capable of being monitored with a register system and our experience so far suggests that this system should play a valuable part in preventing avoidable ill health due to inherited tumour syndromes.

We thank all our clinical colleagues in Wales for their support, particularly Mr Malcolm Wheeler, Mrs Lynn Beck, Professor Reg Hall, and Professor Dilwyn Williams for their interest, Drs Susan Huson, Oliver Quarrell, and Alan Fryer for help in following families, and Dr Mansoor Sarfarazi for computing advice. We thank Dr Marcelle Jay and the staff of the St Mark's polyposis registry for their cooperation, and the Imperial Cancer Research Fund for its financial support.

1 Lynch HT, Lynch J, Lynch P. Management and control of familial cancers In: Mulvihill JJ, Miller RW, Fraumeni JF Jr, eds. Genetics and human cancer. New York: Raven Press, 1977.

2 Emery AEH, Brough C, Crawfurd M, Harper P, Harris R, Oakshott G. A report on genetic registers. $\mathcal{F}$ Med Genet 1978:15:435-42.

3 Harper PS. Genetic registers and the prevention of inherited disorders. In: Carter CO, ed. Developments in human reproduction. London: Academic Press, 1983:117-37.

4 Huson SM, Harper PS, Hourihan MD, Cole G, Weeks RD, Compston DAS. Cerebellar haemangioblastoma and von Hippel-Lindau disease. Brai 1986;109:1297-310.

5 Chapman PD, Church W, Burn J, Gunn A. Congenital hypertrophy of retinal pigment epithelium: a sign of familial adenomatus polyposis. $\mathrm{Br}$. Med $\mathcal{J}$ 1989;298:353-4.

6 Friend SH, Bernards R, Rogelj S, et al. A human DNA segment with properties of the gene that predisposes to retinoblastoma and osteosarcoma Nature 1986;323:643-6.

7 Seizinger BR, Rouleau GA, Ozelius LJ, et al. Von Hippel-Lindau disease maps to the region of chromosome 3 associated with renal cell carcinoma. Nuture 1988;322:268-9.

8 Simpson NE, Kidd KK, Goodfellow PJ, et al. Assignment of multiple endocrine neoplasia type $2 \mathrm{~A}$ to chromosome 10 by linkage. Nature 1987;328:528-30.

9 Bodmer WF, Bailev CJ, Bodmer J, et al. Localisation of the gene for familia adenomatous polyposis on chromosome 5. Nature 1987;328:614-6.

10 Scheffer H, Kema IP, Kondo I, van der Veen AY, Ikeuchi T, Buys CHCM Localisation at a subband level of polymorphic 13q14 DNA probes for diagnosis of hereditary retinoblastoma and Wilson disease. Hum Giene 1987;77:335-7

11 Greger V, Kerst S, Messmer E, Hopping W, Passarge E, Horsthemke B Application of linkage analysis to genetic counselling in families with hereditary retinoblastoma. F Med Genet 1988;25:217-21.

(Accepted 17 April 1989) 